\title{
A Modified Cellular Automaton Approach for Mixed Bicycle Traffic Flow Modeling
}

\author{
Xiaonian Shan, ${ }^{1}$ Zhibin $\mathrm{Li}^{2}{ }^{2}$ Xiaohong Chen, ${ }^{1}$ and Jianhong $\mathrm{Ye}^{1}$ \\ ${ }^{1}$ Key Laboratory of Road and Traffic Engineering of Ministry of Education, Tongji University, 4800 Cao'an Road, \\ Shanghai 201804, China \\ ${ }^{2}$ School of Transportation, Southeast University, 2 Sipailou, Nanjing 210096, China
}

Correspondence should be addressed to Xiaonian Shan; 3ashan@tongji.edu.cn

Received 19 March 2015; Accepted 25 June 2015

Academic Editor: Gabriella Bretti

Copyright (C) 2015 Xiaonian Shan et al. This is an open access article distributed under the Creative Commons Attribution License, which permits unrestricted use, distribution, and reproduction in any medium, provided the original work is properly cited.

\begin{abstract}
Several previous studies have used the Cellular Automaton (CA) for the modeling of bicycle traffic flow. However, previous CA models have several limitations, resulting in differences between the simulated and the observed traffic flow features. The primary objective of this study is to propose a modified CA model for simulating the characteristics of mixed bicycle traffic flow. Field data were collected on physically separated bicycle path in Shanghai, China, and were used to calibrate the CA model using the genetic algorithm. Traffic flow features between simulations of several CA models and field observations were compared. The results showed that our modified CA model produced more accurate simulation for the fundamental diagram and the passing events in mixed bicycle traffic flow. Based on our model, the bicycle traffic flow features, including the fundamental diagram, the number of passing events, and the number of lane changes, were analyzed. We also analyzed the traffic flow features with different traffic densities, traffic components on different travel lanes. Results of the study can provide important information for understanding and simulating the operations of mixed bicycle traffic flow.
\end{abstract}

\section{Introduction}

In recent years, bicycle has been considered an important mode of transport within urban areas to relieve traffic congestion and reduce gas emission. Many governments in the world have proposed numerous policies and strategies to improve the level of service of bicycle traffic to promote bicycle use $[1,2]$. For example, London has invested a lot of money to build bikeways [1]. The daily average number of cycle trips has increased from 0.3 million in 1993 to 0.5 million in 2011 in London. With the increase of bicycle travel demand, it is important to understand the characteristics of bicycle traffic flow to improve the level of service for cycling [3-6].

Previously, numerous studies regarding bicycle traffic have been conducted. Previous studies mainly focused on two features in bicycle traffic flow: (1) the key parameters of bicycle traffic and (2) the passing maneuvers in bicycle traffic. In the former subject, many studies have investigated the operating speed, speed variation, and capacity of bicycle traffic on different bicycle facilities [7-11]. Field observations were usually conducted to investigate such parameters. For example, Chen et al. found that the capacity of a bicycle lane is about $2000 \mathrm{bic} / \mathrm{h} / \mathrm{lane}$ [7]. Lin et al. reported that the speed of bicycle is around $10-30 \mathrm{~km} / \mathrm{h}$ in free-flowing bicycle traffic [9].

Some other studies explored the characteristics and number of passing events in bicycle traffic [12-17]. Hummer and Rouphail noticed that bicycle passing maneuvers were naturally produced due to the variation in bicycle speeds [12]. The Highway Capacity Manual (TRB 2010) recommends using the methods proposed by Hummer and Rouphail to estimate the number of passing maneuvers in bicycle traffic on off-street bicycle facilities [13]. Li et al. proposed a method to model bicycle passing maneuvers on multilane bicycle paths. They used field observations to calibrate and validate the models [14]. Chen et al. studied the characteristics of distances and speeds of bicycles during the whole process of passing events from the microcosmic aspects $[15,16]$. 
In previous observational studies, only some parts of bicycle traffic flow features were observed on bicycle paths. For example, since congestion rarely occurs in bicycle traffic, observing the capacity and operational feature in congested bicycle traffic are quite difficult. As a consequence, with the shortage of limited data in field observation, simulation has been increasingly considered a surrogate approach for understanding bicycle traffic flow features to support decision making when traffic condition changes.

Several previous studies have proposed the Cellular Automaton (CA) to simulate bicycle traffic operations [1821]. For example, Gould and Karner built a CA model for bicycle traffic flow considering the probability of lane changes [18]. Zhao et al. developed a CA model considering the forward distances for lane changes [19]. After a review on previous studies, it was found that previous CA models have the following issues: (1) some rules in the model were unrealistic and (2) previous model was not well developed to capture the capacity and passing maneuvers in bicycle traffic. Besides, as electric bicycle (e-bicycle) is growing quickly in China and some other countries [6], it is important to consider the behaviors of e-bicycle in the CA modeling and evaluate the features in the mixed bicycle traffic.

The primary objective of this study is to analyze the features of mixed bicycle traffic flow using a modified CA model. More specifically, this study includes the following three tasks: (1) to propose a modified CA model considering actual behaviors of cyclers; (2) to compare the simulation results of our and previous CA models with field observations; and (3) to analyze the operational features in different mixed bicycle traffic conditions. In the following section, data collection is introduced. In Section 3, the development of CA model is presented. Section 4 compares the results of different CA models. Section 5 shows the characteristics in mixed bicycle traffic flow. The paper ends with brief concluding remarks in Section 6.

\section{Data}

Field data collection was conducted to calibrate the simulation model and to validate the simulating results. Four types of information were obtained during the investigation: (1) the speed of bicycle in free-flow traffic including e-bicycle and conventional bicycle (c-bicycle), which can be calculated through the time difference for a bicycle passing two different road sections; (2) the flow of bicycle through a certain road section; (3) the density of the study area through recording the number of bicycles at a certain moment; and (4) the number of passing events for each bicycle during a certain time. This information was extracted from videos using the method in [22].

As suggested by Transportation Planning of Urban Road in China [23], the most common width of bicycle path is 3.5 meters in cities of China, indicating that the number of bicycle lanes is 3 [24]. Therefore, in this study, Wuning Road, an arterial road in Shanghai with the width of $3.5 \mathrm{~m}$, is selected as the field observation site, as shown in Figure 1. The lane is a dedicated nonmotorized vehicle lane without interruption from pedestrians and motor vehicles. The observation site is

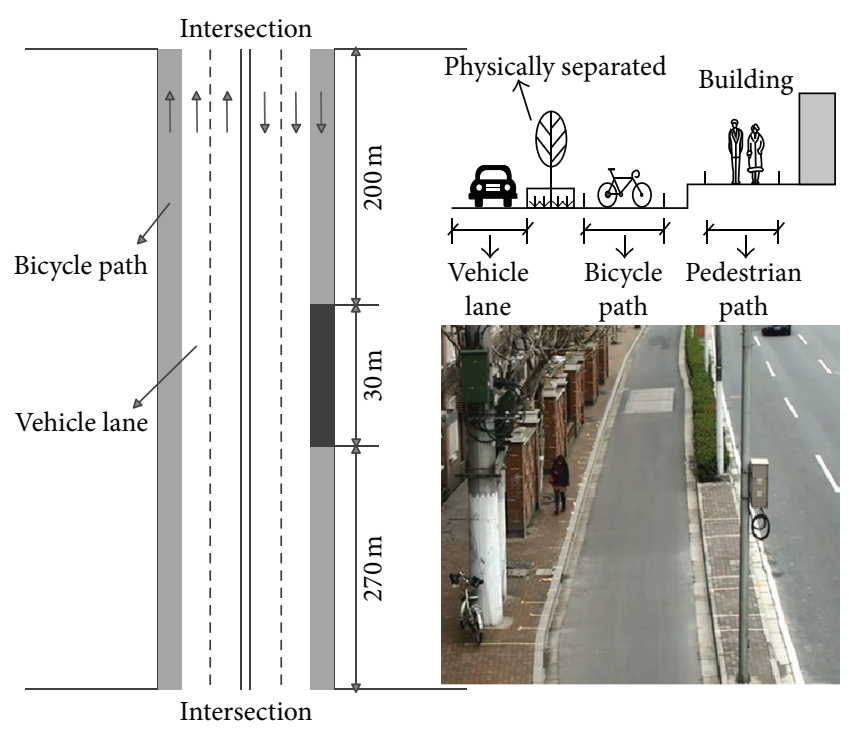

Study area

FIgURE 1: Layout of the data investigation site.

located in the mid-block with 300 meters to the downstream intersection and 200 meters to the upstream intersection. So it can be assumed that the nonmotorized vehicles are not affected by traffic control at the intersections.

Video camera was placed on the pedestrian overpass to achieve an adequate viewing angle. Traffic information was recorded during the two weekdays from 7:30 a.m. to 9:00 a.m., which covers peak and nonpeak periods. Video tapes were later reviewed to obtain the speed of each bicycle in free-flowing traffic and flow of the bicycle under the different densities. The number of passing events of each bicycle was recorded considering the different densities. The length of the study section was 30 meters and the time interval was 30 seconds in this study [22].

In our dataset, the maximum of flow is $2250 \mathrm{bic} / \mathrm{h} /$ lane when the density is $133.3 \mathrm{bic} / \mathrm{km} /$ lane, which is consistent with the others $[7,11]$. The number of passing events ranges from 0 to 58 per minute. The average speed of e-bicycle is about $24 \mathrm{~km} / \mathrm{h}$, which is larger than the speed of c-bicycle (which is $17 \mathrm{~km} / \mathrm{h}$ ). The proportion of electric bicycle is $80 \%$. The summary statistics of bicycle traffic flow information are shown in Table 1.

\section{Method}

In this section, the basic CA model was first described. Then the modified CA model was proposed for modeling mixed bicycle traffic flow. The parameter calibration in the CA model with the genetic algorithm was presented.

3.1. Basic Cellular Automaton. In the early 1990s, Nagel and Schreckenberg proposed the famous CA model, as a basic CA model for simulating the traffic flow, called NaSch model [25]. It is defined on a one-dimensional lattice of $L$ sites with periodic boundary conditions. Each site is either occupied by 
TABLE 1: Summary statistics of bicycle traffic information.

\begin{tabular}{|c|c|c|c|c|c|c|}
\hline \multirow[b]{2}{*}{ Indicator } & \multicolumn{2}{|c|}{ Flow and density } & \multicolumn{2}{|c|}{ Number of passing events } & \multicolumn{2}{|c|}{ Speed in free flow } \\
\hline & $\begin{array}{c}\text { Flow } \\
\text { (bic/h/lane) }\end{array}$ & $\begin{array}{c}\text { Density } \\
\text { (bic/km/lane) }\end{array}$ & $\begin{array}{l}\text { Number } \\
\text { (per min) }\end{array}$ & $\begin{array}{c}\text { Density } \\
\text { (bic/km/lane) }\end{array}$ & $\begin{array}{c}\text { e-bicycle } \\
(\mathrm{km} / \mathrm{h})\end{array}$ & $\begin{array}{c}\text { c-bicycle } \\
(\mathrm{km} / \mathrm{h})\end{array}$ \\
\hline Sample & 153 & 153 & 147 & 147 & 537 & 334 \\
\hline Mean & 803 & 40.6 & 13 & 38.5 & 24 & 17 \\
\hline SD & 448 & 25.0 & 11 & 21.6 & 5 & 3 \\
\hline Min & 80 & 3.7 & 0 & 3.7 & 13 & 8 \\
\hline Max & 2250 & 133.3 & 58 & 100 & 38 & 24 \\
\hline
\end{tabular}

a vehicle or empty. The velocity of each vehicle is an integer from zero to $v_{\max }$, with $v_{\max }$ meaning the maximum speed of a vehicle. If $x_{n}(t)$ denotes the position of the $n$ vehicle at time $t$, the position of the car ahead of it at time $t$ is $x_{n+1}(t)$.

The system evolves based on the synchronous rules given by the following.

Step 1. Acceleration: consider $v_{n}(t+1) \rightarrow \min \left(v_{n}(t)+\right.$ $\left.1, v_{\max }\right)$.

Step 2. Collision avoidance: consider $v_{n}(t+1) \rightarrow \min \left(v_{n}(t+\right.$ 1), $\left.d_{n}(t)\right)$.

Step 3. Randomization: with probability $p, v_{n}(t+1) \rightarrow$ $\max \left(v_{n}(t+1)-1,0\right)$.

Step 4. Movement: consider $x_{n}(t+1)=x_{n}(t)+v_{n}(t+1)$.

Where $d_{n}(t)$, denoting the gap (number of empty sites) between cars $n$ and $n+1$, can be given by $d_{n}(t)=x_{n+1}(t)-$ $x_{n}(t)-1$.

3.2. Modified Cellular Automaton. An important shortage of $\mathrm{NaSch}$ model is that there are no passing events in the traffic flow, which is not in accord with the fact. For multilane $(\geqslant 3)$ traffic flow, the process of vehicle updating can be divided into two parts: (1) vehicle lane changing based on the rules of lane changes and (2) after the lane changing vehicle of each lane updating based on the NaSch model [26]. So the difference among multilane CA models is essentially the difference among the rules of lane changes.

To simulate bicycle traffic flow, previous studies proposed rules of lane changes considering the forward distances [27, 28]. However, some researchers have found that cyclists have the feature for riding on the right side $[14,15]$, which means that cyclists will choose the right lane as their riding lane and the left lane as their passing lane when the riding condition in the right lane is the same as the current lane or could not affect the normal riding. Therefore, a modified Cellular Automaton model has been proposed in this paper considering this feature to simulate the characteristics of mixed bicycle traffic flow, referring to Pedersen's CA model which is used for entry ramps [29]. The rules of lane changes in this paper are as follows.

Rule 1. Considering the right lane, if $d_{n}^{r-}(t) \geq v_{\max }$ and $d_{n}^{r+}(t) \geq d_{n}^{+}(t)$, so new_l $l_{n}(t)=$ lane $_{n}(t-1)-1$; else new_l $l_{n}(t)=$ lane $_{n}(t-1)$.
Rule 2. Considering the left lane, if $d_{n}^{l-}(t) \geq v_{\max }$ and $d_{n}^{+}(t)<$ $d_{n}^{l+}(t)$ and $d_{n}^{r+}(t)<d_{n}^{l+}(t)$ and $\left[d_{n}^{+}(t)<\min \left(v_{n}(t)+1, v_{\max }\right)\right.$ or $\left.v_{n}(t)=0\right]$, so new $l_{n}(t)=$ lane $_{n}(t-1)+1$.

Rule 3. Lane changing: with probability $P_{\mathrm{lc}}$, let lane $\mathrm{l}_{n}(t)=$ new $l_{n}(t)$ if possible. Handle the lanes one by one from right to left to avoid potential collisions.

Where $d_{n}^{x y}(t)$ denoting the number of empty cells (the gap) in time step $t$ between bicycle $n$ and the closest bicycle in some direction. $x$ could be $l / r$ or not be present, representing the left lane/right lane or current lane. $y$ is either + or $-:+$ means that the bicycle is ahead of bicycle $n$; - means that the bicycle is behind of bicycle $n$. new $l_{n}(t)$ means the desired lane.

Rule 1 represents the fact that the rider changes to the lane on the right, if moving to it will not cause any immediate problems and the gap ahead of him is better than the gap in the current lane. Rule 2 simulates the fact that the rider should only select the lane to the left lane if it is "better" than the current lane and that to the right lane, and if the driver wants to be riding faster in the next time step than the current lane allows.

Moreover, considering the acceleration difference between e-bicycle and c-bicycle, Step 1 of acceleration to ebicycle should be modified to $v_{n}(t+1) \rightarrow \min \left(v_{n}(t)+2\right.$, $\left.v_{\text {emax }}\right)[19]$. The other steps to the two types of bicycle remain the same.

In the simulation, flow is calculated for each lane. Density of a lane is obtained in every simulation step. The average flow and density can be then calculated. Passing events are calculated by the position of every bicycle at every simulation step. The total number of passing events for each bicycle during the simulation steps is then calculated [19]. The total number of lane changes could be calculated based on Rule 3 .

3.3. Parameters Calibration. Six parameters need to be calibrated in the CA model, which are the cell size, the maximum velocity of e-bicycle $\left(v_{\text {emax }}\right)$, the maximum velocity of cbicycle $\left(v_{\mathrm{cmax}}\right)$, the probability of randomization for e-bicycle $\left(p_{\text {re }}\right)$, the probability of randomization for c-bicycle $\left(p_{\mathrm{rc}}\right)$, and the probability of lane changing $\left(p_{\mathrm{lc}}\right)$. Cell size is mainly based on the congestion density and bicycle's physical size. We adopted 2 meters as the length of a bicycle cell, consistent with other models $[19,27,28]$. According to the field observations, as shown in Table $1, v_{\text {emax }}=10 \mathrm{~m} / \mathrm{s}=5$ cells' length $/ \mathrm{s}$ and 
$v_{\text {cmax }}=6 \mathrm{~m} / \mathrm{s}=3$ cells' length $/ \mathrm{s}$. The number of lanes is 3 , and the proportion of electric bicycle is 0.8 .

Previous studies usually calibrated the parameters using the trial and error method [18, 19], which may not have good simulation results for field observed data. A good method of calibrating traffic simulation models is based on the fundamental diagram [30], which is adopted in this paper. Furthermore, genetic algorithm (GA) is a stochastic search method based on the principles and mechanisms of natural selection and "survival of the fittest" from natural evolution, which has been widely used in the field of calibrating microscopic traffic simulation models [31]. The processes of GA are as follows: (1) construct an initial population of chromosomes; (2) evaluate the fitness of each chromosome; (3) perform fitness scaling if necessary; (4) select the mating pairs of chromosomes; (5) create new offspring through crossover and mutation operations; (6) form a population for the next generation; and (7) if process has converged, return the best chromosome as the solution; otherwise go to step (2).

In this study, the GA was used to calibrate the three probability parameters. The number of population sizes is 10 , the maximum number of iterations is 200 , and the values of probability of crossover and mutation operations are 0.8 and 0.005 . The function of fitness is to calculate the error based on the fundamental diagram given by

$$
\text { Fitness }=\frac{\left|k_{s}-k_{r}\right|}{k_{r}}
$$

where $k_{r}=18.56$, based on the fit function of actual data $\left(Q_{r}=18.56 \times D, 3.7<D<133.3, R^{2}=0.69\right), Q_{r}$ means the flow (bic/h/lane), and $D$ means the density (bic/km/lane). $k_{s}$ was based on the fit function of simulation data $\left(Q_{s}=k_{s} \times D\right.$, $0<D<140$ ).

Time to calculate a value of fitness is about $1 \mathrm{~min}$, so the time for parameters calculation is almost $2000 \mathrm{~min}$, about 33 hours, using MATLAB R2009b for model implementation. As a result, the calculated values of $p_{\mathrm{re}}, p_{\mathrm{rc}}$, and $p_{\mathrm{lc}}$ are $0.1,0.2$, and 0.9 , respectively. The minimum value of fitness is 0.058 , as shown in Figure 2.

\section{Comparison between Different Models}

In this section, the simulated bicycle traffic flow features were compared with field observations. For comparison purpose, the CA models in some previous studies were also estimated $[18,19]$. The simulation results of several different models were compared in this section.

4.1. Comparison of Relationship between Flow and Density. The relationship between flow and density is important to the determination of fundamental diagram. The scatter of relationship between flow and density in the field observation is shown in Figure 3. It is obvious that the flow increases from 0 to $2250 \mathrm{bic} / \mathrm{h} / \mathrm{lane}$ with the increase of density, indicating that the observed traffic data are in free-flow condition. Three CA models including our model, Zhao's model, and Gould's model were estimated. The simulated traffic flow versus density data is also shown in Figure 3.

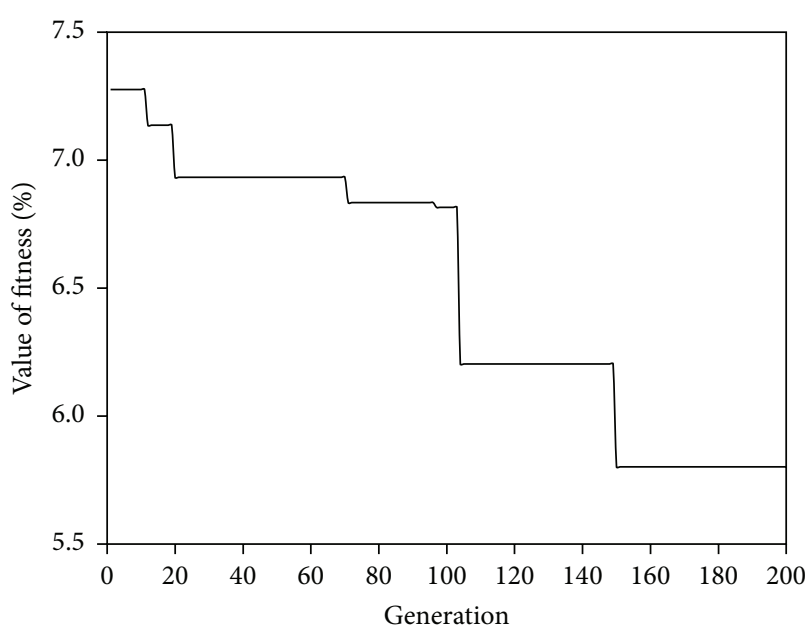

Figure 2: The fitness value in each generation.

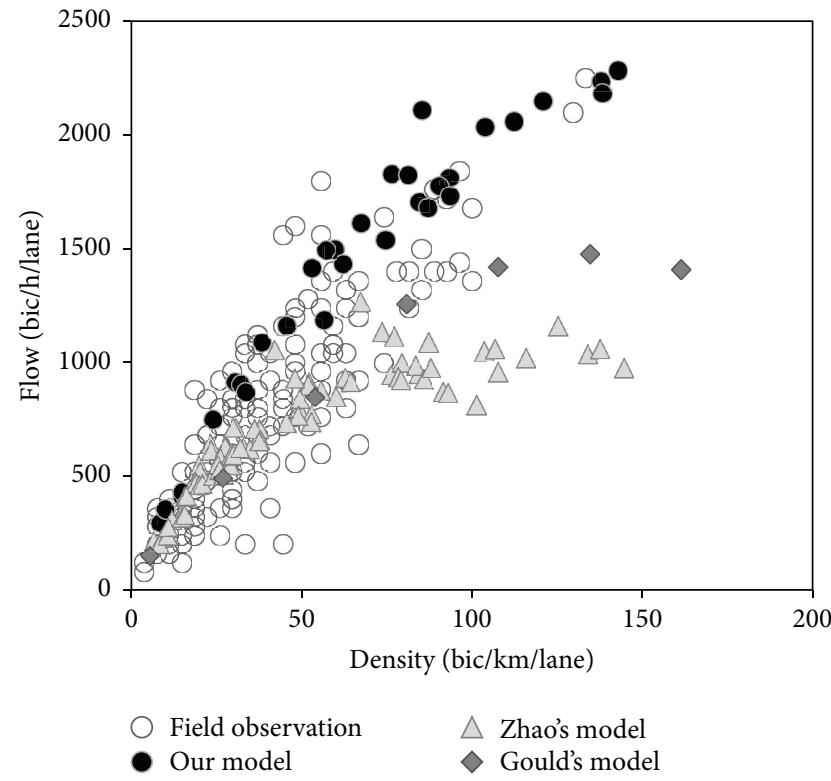

FIGURE 3: Comparison of flow-density relationship.

Among the three models, the modified CA model proposed in this study produces the closest simulation to field observation. Both Zhao's model and Gould's model result in a lower capacity of bicycle traffic as compared with field observations and our model. The capacity in their models is about 1200 and $1500 \mathrm{bic} / \mathrm{h} / \mathrm{lane}$, respectively. The reason for the lower capacity in Zhao's model is that the probability of randomization is 0.45 which is much larger than reality and also without considering the probability of lane changing. For Gould's model, rules of lane changes were based on the two-lane case proposed by Rickert et al. [32], which was symmetrical by lanes without considering the feature of cyclists for riding on the right side.

Because of the stochastic and dispersive features of data, as shown in Figure 3, we first made fitted curves of field observation and simulation models, and then the area 
TABLE 2: Value of $\varphi$ to different models.

\begin{tabular}{lccc}
\hline Models & Fit function & Adjusted $R^{2}$ & \\
\hline Field observation & $f_{\text {field }}=15.4 \times D+179.39$ & 0.73 & 0 \\
Our model & $f_{\text {our }}=-0.092 \times D^{2}+28.16 \times D+80.19$ & 0.97 & 27168 \\
Zhao's model & $f_{\text {Zhao }}=-0.083 \times D^{2}+17.24 \times D+159.99$ & 0.88 & 60069 \\
Gould's model & $f_{\text {Gould }}=-0.076 \times D^{2}+21.17 \times D+1.68$ & 0.99 & 37734 \\
\hline
\end{tabular}

errors between field observation and different models were calculated to show the best model quantitatively, given by

$$
\varphi=\left|\int_{D_{1}}^{D_{2}}\left(f_{\text {model }}-f_{\text {field }}\right) d D\right| \quad(D \in(0,140)),
$$

where $\varphi$ denotes the area error between the result of a certain model and field observation, $f_{\text {field }}$ means the fit function of actual data, $f_{\text {model }}$ denotes the fit function of model, and $D$ means the density. The fit function to the three models chooses the two-polynomial function for high regression. Furthermore, we did not find the declining trend of flow, so the linear regression is selected for fitting the field observation. Results were shown in Table 2.

Among the three models, our modified CA model has the lowest area error with the value of 27168, indicating that our model produces more accurate simulation results for flow-density relationship in the mixed bicycle traffic flow. Furthermore, Gould's model is better than Zhao's model with the value of 37734 and 60069 , respectively.

4.2. Comparison of Number of Passing Events. Passing events indicate the speed difference among bicycles that bicycles with high speed can overtake the bicycles with low speed. In this study, the standardized number of passing events is calculated according to the following equation:

$$
\begin{aligned}
& N_{\text {handled-sim }}(D) \\
& =\frac{N_{\text {total }}(D) \times \text { study_area } \times 60}{\text { simulation_step } \times \text { road_length } \times \text { lanes }}, \\
& N_{\text {handled-field }}(D)=\frac{N_{\text {total }}(D) \times 60}{\text { time_interval }},
\end{aligned}
$$

where in this study simulation_step is 100 , road_length is 200 , lanes are 3, study_area is $30 \times 3=90$, and 60 means 1 minute. For field observation, the time_interval is $30 \mathrm{~s}$.

The comparison of number of passing events between simulation of different models and field observation is shown in Figure 4. Within the range of observed density, the number of passing events increases with the increase of density. It is observed that the simulation of our model is more close to field observation as compared to Zhao's model. The reason may be that in Zhao's model every bicycle can take lane changes easily to obtain high speed. It is too difficult to adopt method of quantitative analyses because of the data discretization and lack of the knowledge of the relationship between the number of passing events and density.

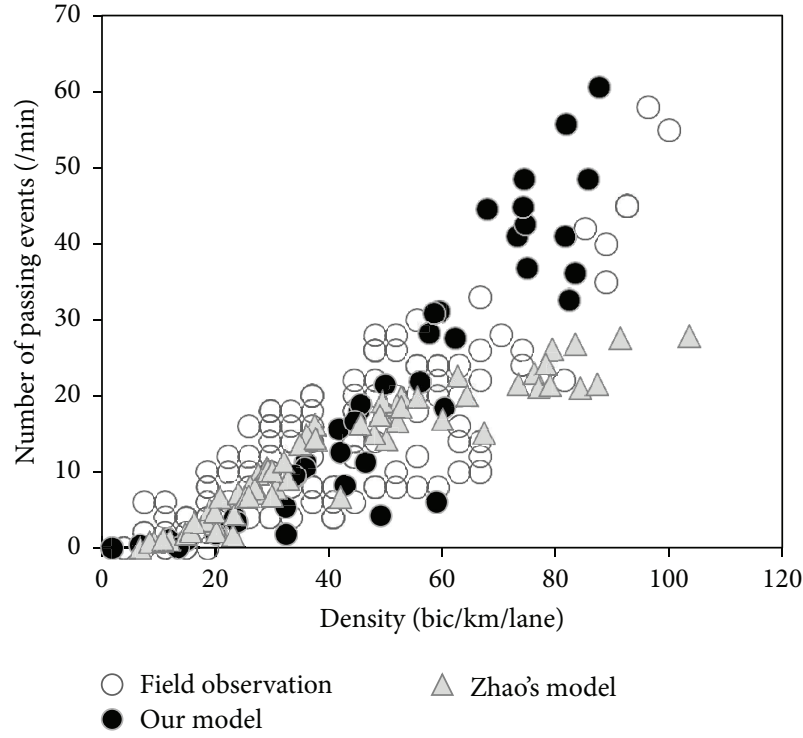

Figure 4: Comparison of number of passing events.

\section{Results of Simulation Analysis}

Results in the above section showed that our model produced more accurate simulation of bicycle traffic than previous models. In this section, the characteristics of mixed bicycle traffic flow under different conditions were analyzed based on the modified CA model. The fundamental diagram of bicycle traffic was first analyzed. The number of passing events and lane changes were analyzed. The traffic flow features under different densities, traffic components, and travel lanes were also analyzed.

5.1. Analysis of Fundamental Diagram. The fundamental diagram was constructed with the three CA models, as shown in Figure 5. It is observed that, in general, the fundamental diagram presents a triangular shape in each model. Traffic flow increases first as the increase of density and then decreases when density continuously increases. The most significant difference among the three models is the capacity of a bicycle lane. The capacity in our model is $2300 \mathrm{bic} / \mathrm{h} / \mathrm{lane}$, while it is $1500 \mathrm{bic} / \mathrm{h} /$ lane in Gould's model and $1300 \mathrm{bic} / \mathrm{h} / \mathrm{lane}$ in Zhao's model. The critical density is $150 \mathrm{bic} / \mathrm{km} / \mathrm{lane}$ in our model and Gould's model. But in Zhao's model the critical density is about $80 \mathrm{bic} / \mathrm{km} / \mathrm{lane}$. Besides, our model and Gould's model have similar result regarding the slope of congested fundamental diagram, but Zhao's model has a quite different result. 


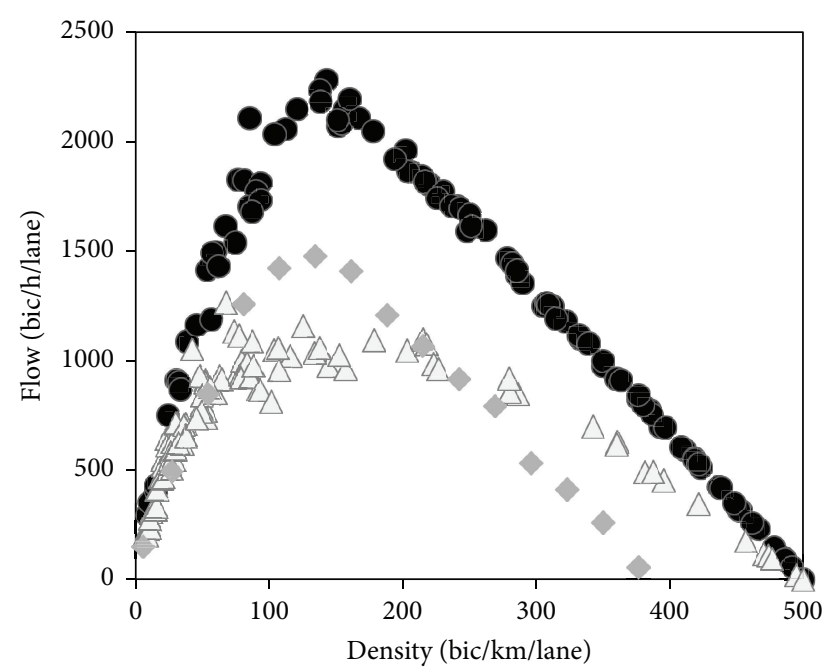

- Our model $\triangle$ Zhao's model

FIGURE 5: Simulation of fundamental diagram.

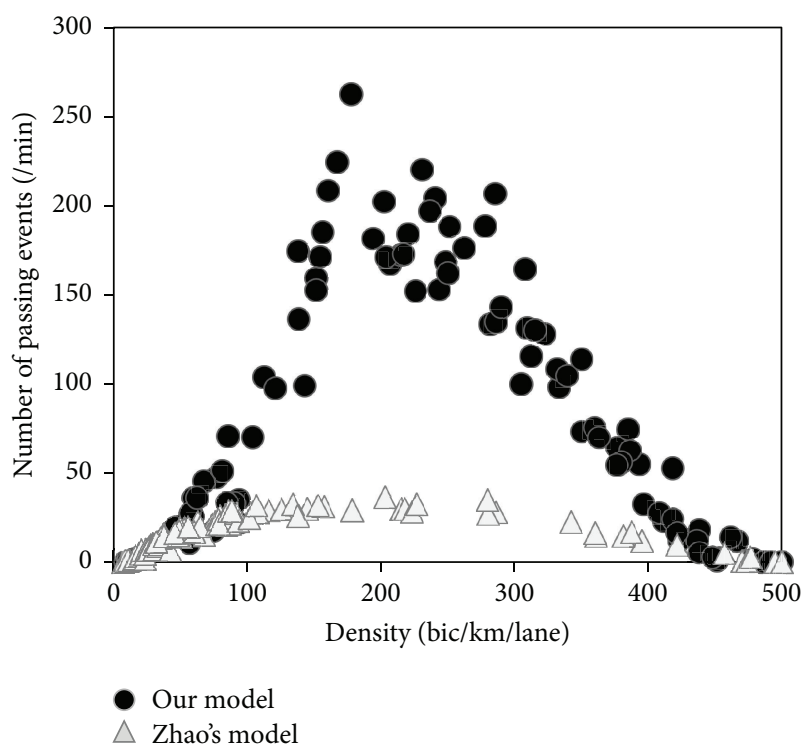

FIGURE 6: Simulation of number of passing events.

5.2. Analysis of Number of Passing Events. The number of passing events under different traffic densities is shown in Figure 6. In our model, the number of passing events increases with the increase of density when density is less than $200 \mathrm{bic} / \mathrm{km} /$ lane. When density is larger than $200 \mathrm{bic} / \mathrm{km} / \mathrm{lane}$, the number of passing events decreases because in congested traffic the overtaking behavior becomes more difficult. What is more, the maximum number of passing events is about 250 per minute which is much larger than that in Zhao's model. In our model, cyclists can ride with the desired speed with more passing events than Zhao's model. And the traffic flow in our model is more stable than Zhao's model. According to Figures 5 and 6, with the lower

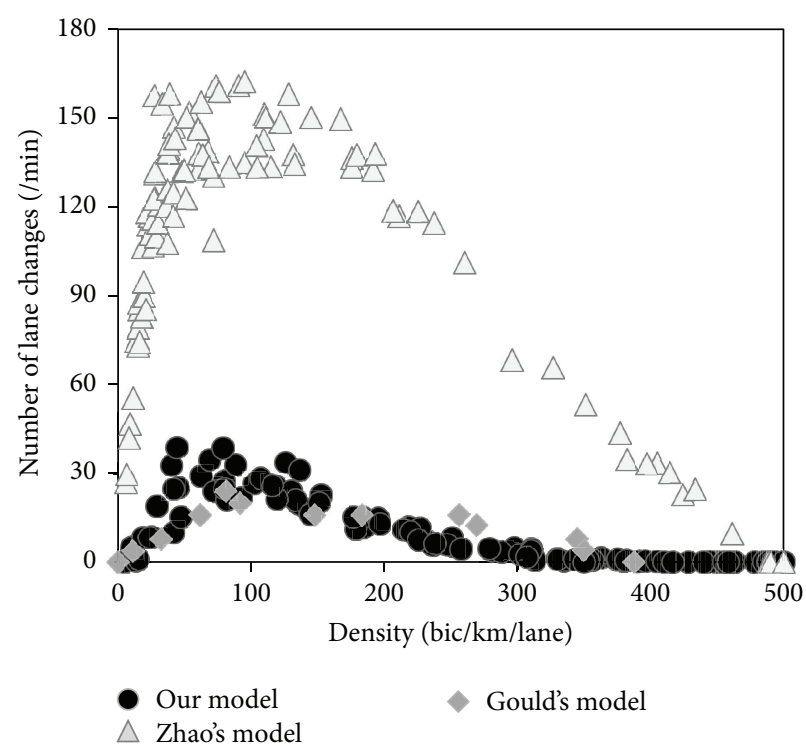

FIGURE 7: Simulation of number of lane changes.

capacity and passing events, Zhao's model may not produce accurate evaluation for the level of service in bicycle traffic.

5.3. Analysis of Number of Lane Changes. The relationship between the number of lane changes and traffic density is shown in Figure 7. With the increase of traffic density, the number of lane changes first increases and then decreases. The density that corresponds to the largest number of lane changes is about $100 \mathrm{bic} / \mathrm{km} / \mathrm{lane}$, which is a little lower than the critical density (that corresponds to the capacity). It is also observed that the number of lane changes is quite different in different models. In Zhao's model, the number of lane changes is up to 160 per minute, while in our model and Gould's model it is 40 and 30 per minute, respectively. Our model and Gould's model have consistent findings. After a close examination, we found that the rule of lane changes in Zhao's model is too simple without considering the backward safety and the probability of lane changes. Thus, it results in unrealistic lane changing behaviors.

5.4. Analysis of Bicycle Traffic Flow Features. Bicycle traffic flow features under different conditions were evaluated in this section. The time-position diagram was used for the analysis of traffic condition. During simulation, the position of each bicycle at each time step was recorded to plot the diagram. In the time-position diagram, the $x$-axis means the time (s) and the $y$-axis means the position (cell). Each line in the diagram means a trajectory of a bicycle and the slope of line represents its speed.

5.4.1. Traffic Flow Features under Different Traffic Densities. Traffic flow features under different densities to our model are shown in Figure 8(a). With the increase of density, the interaction between bicycles becomes more severe. The bicycle flow turns from fluency into disorder, and the speed of bicycle first becomes the maximum and then decreases. 


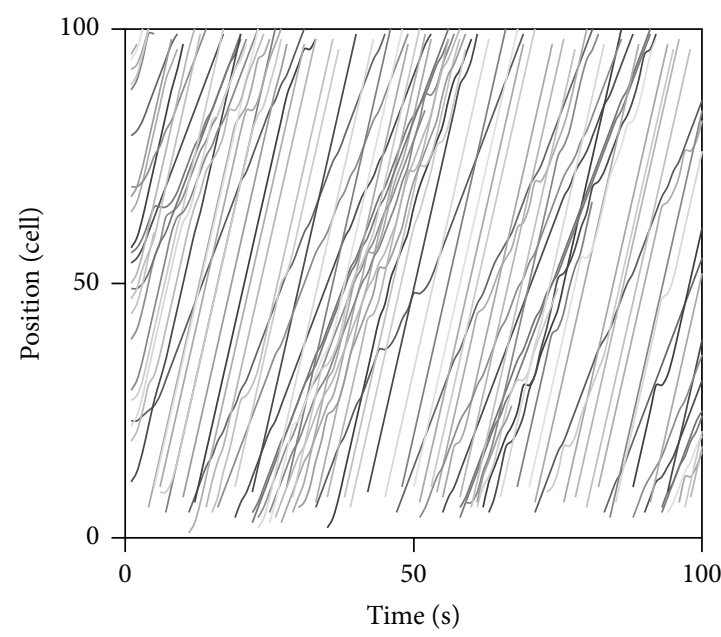

(a1) $k=50 \mathrm{bic} / \mathrm{km} / \mathrm{lane}$

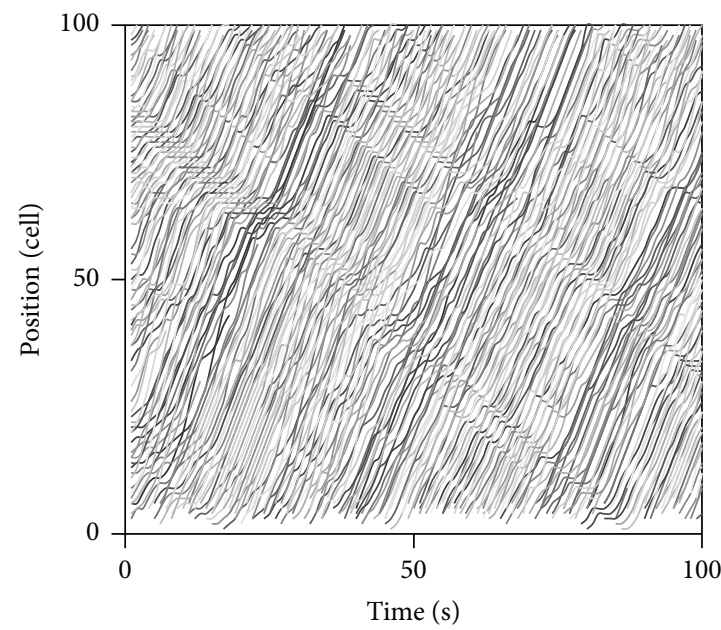

(a2) $k=150 \mathrm{bic} / \mathrm{km} /$ lane

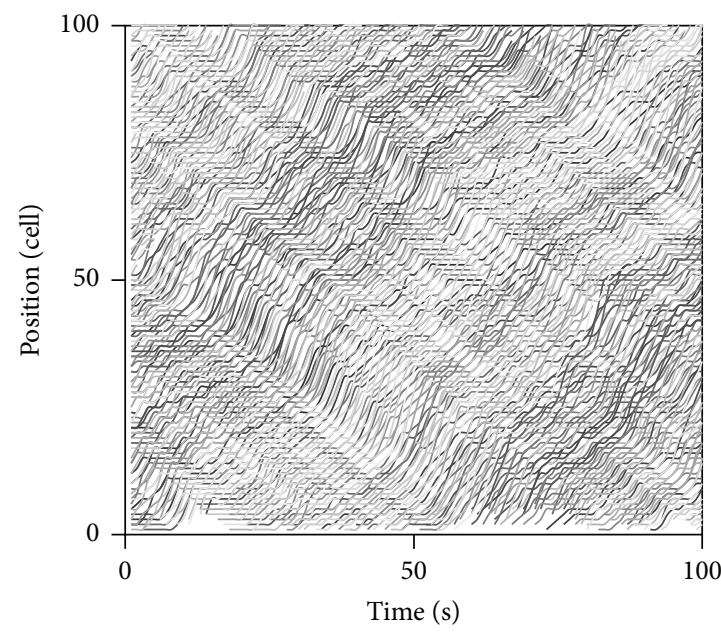

(a3) $k=250 \mathrm{bic} / \mathrm{km} /$ lane

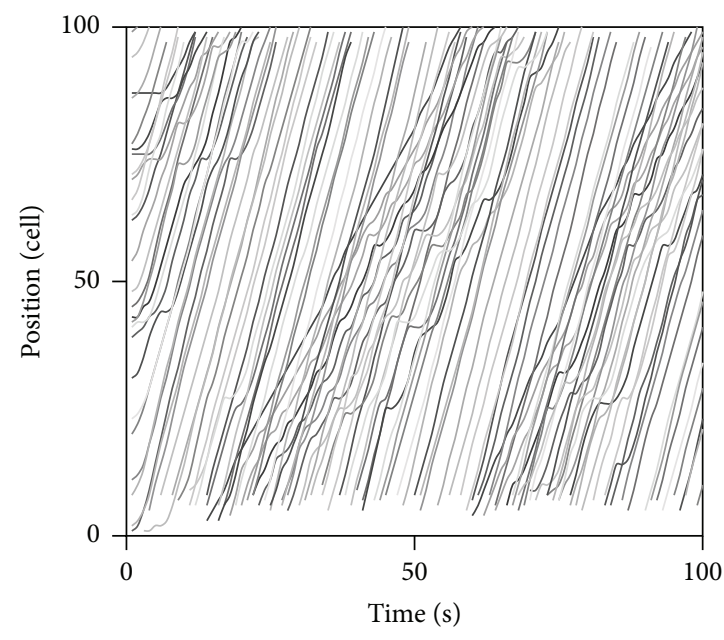

(b1) $k=50 \mathrm{bic} / \mathrm{km} / \mathrm{lane}$

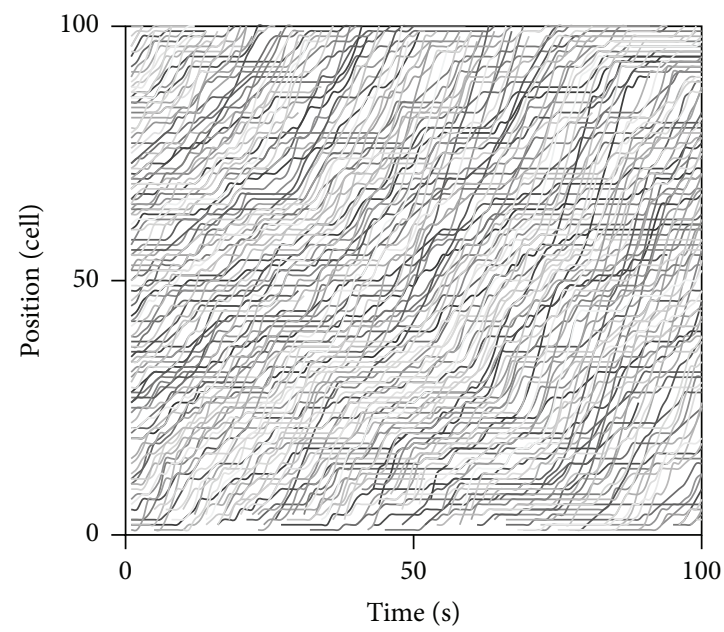

(b2) $k=150 \mathrm{bic} / \mathrm{km} / \mathrm{lane}$

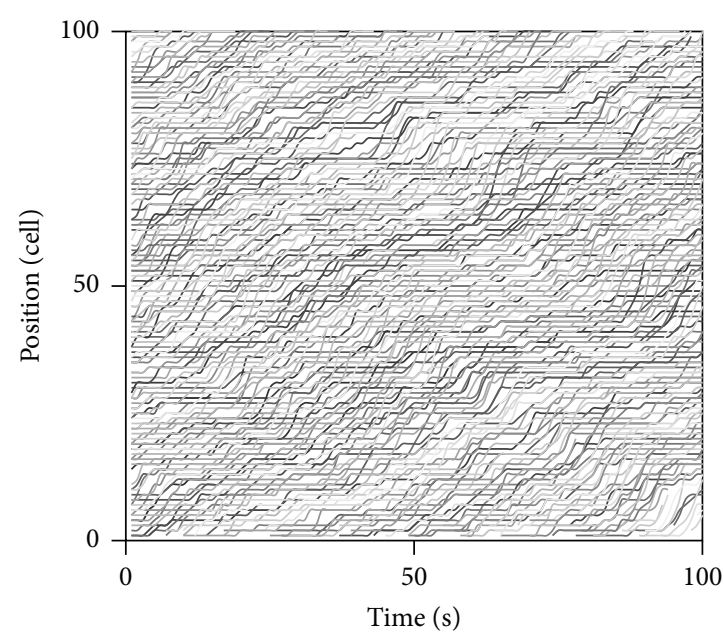

(b3) $k=250 \mathrm{bic} / \mathrm{km} /$ lane

FIgURE 8: Traffic conditions under different densities: (a) our model; (b) Zhao's model. 
When the density is low, cyclists can ride with their desired speed, and the traffic flow is stable with the free riding speed (see Figure 8(a1)). When the density increases, traffic flow becomes a little disorder and riding speed decreases (see Figure 8(a2)). At the high density, the traffic flow contains turbulence with high fluctuation of speed and the high interaction between bicycles (see Figure 8(a3)).

The time-position diagram of bicycle traffic in Zhao's model was also constructed as shown in Figure 8(b). Due to the inaccurate capacity of bicycle lane, the differences of bicycle traffic features are very clear. At the low density ( $50 \mathrm{bic} / \mathrm{km} / \mathrm{lane}$ ), both of the two models produce stable traffic with high speed (see Figure 8(b1)). As density increases to near $150 \mathrm{bic} / \mathrm{km} /$ lane, bicycle traffic in Zhao's model becomes disordering (see Figure 8(b2)), while our model can keep a higher flow and speed. For the congested density (250 bic/km/lane), both of the time-position diagrams show a trend of disorder, but Zhao's model is more turbulent than our model (see Figure 8(b3)).

\subsubsection{Traffic Flow Features under Different Traffic Compo-} nents. On other roads or in other cities, the proportion of electric bicycle could be different resulting in different traffic flow features. Policy makers would like to know what the traffic situation will be if they promote or ban electric bicycles within urban areas. To answer the question, this section evaluates the traffic flow features under different traffic components. In the simulation different proportions of electric bicycle were specified. The results are shown in Figure 9.

Figures 9 (a) to 9 (c) show the traffic flow conditions with the $20 \%, 50 \%$, and $80 \%$ of electric bicycle. It is observed that, under low density condition, the time-position diagrams show no large differences. The traffic conditions under different components are quite stable. The only difference is that the speeds under larger proportion of electric bicycle are higher. As the traffic density increases, the difference between different components becomes larger. Surprisingly, as shown in Figures 9(b) and 9(c), the traffic condition with small proportion of electric bicycle shows more obvious trends of disorder. The traffic condition with large proportion of electric bicycle is more stable. The reason for the results would be that the speed difference among conventional bicycles is larger than that among electric bicycles. The homogeneity in speeds of electric bicycles results in less passing events and more stable traffic.

5.4.3. Traffic Flow Features on Different Travel Lanes. The above simulation was conducted for bicycle path with 3 travel lanes. On other roads in cities of China, bicycle paths could be 2 lanes or 4 lanes and the traffic flow features could be different on different paths. Policy makers would like to know what the traffic situation will be if they provide more travel lanes or reduce bicycle lanes on bicycle paths. To answer the question, this section evaluates the traffic flow features under different travel lanes. During simulation, the same traffic flow demand was set for all the three scenarios, of which the bicycle demand was $4000 \mathrm{bic} / \mathrm{h}$. The proportion of electric bicycle is set to be 0.8 . The traffic conditions on the 2-lane, 3-lane, and 4-lane bicycle paths are shown in Figure 10.

It is identified that the traffic flow features on bicycle paths are greatly affected by the number of lanes. As shown in Figures 10(a) and 10(b), the bicycle traffic on the 2-lane and 3-lane paths is quite unstable resulting in very low speed and large variation of speeds. The bicycle speeds on the 3lane paths are obviously higher than that on the 2-lane paths. For the same demand level, the traffic condition on the 4lane path is quite stable without significant disturbances in bicycle operations, as shown in Figure 10(c). Policy makers could determine the number of bicycle lanes according to the traffic flow conditions with our proposed CA model.

\section{Conclusions and Discussion}

This study proposed a modified CA model to analyze the characteristics of mixed bicycle traffic flow. Based on the field observations, the parameters in the CA model were calibrated using the genetic algorithm. The simulation results of our model and several previous models were compared with field observations. The features of fundamental diagram, the number of passing events, and the number of lane changes were analyzed with the simulation model. The study also evaluated the traffic flow features under different traffic densities, traffic components, and travel lanes on bicycle paths.

The results showed that the modified CA model produced more accurate simulation of traffic flow features as compared to previous models. The simulation results of our model were more consistent with field observations. Both Zhao's model and Gould's model simulated a lower capacity of bicycle traffic. Besides, our model described the number of passing events more accurately than Zhao's model did. Different models also produced different simulations of fundamental diagram, number of passing events, and number of lane changes. The number of passing events in our model was larger than that in Zhao's model, while Zhao's model produced unrealistic number of lane changes as compared to our model and Gould's model.

The bicycle traffic flow features were affected by the traffic density on bicycle paths. As the density became large, there were large disturbances in bicycle traffic flow with lower speed and larger speed variation. Traffic operation was also affected by the traffic components. The simulation results suggest that if the proportion of electric bicycle is low, the traffic condition is less stable due to the large speed difference among cyclers. Larger proportion of electric bicycle created homogeneous traffic flow with higher speed and smaller speed variation. For the same travel demand, the traffic flow feature presented different features on bicycle paths with different number of travel lanes.

The findings of this study can help better understand the operations of bicycle traffic. More importantly, the modified CA model proposed in our study showed more accuracy than other models in simulating the bicycle traffic, which could be helpful to policy makers. First, our model can 


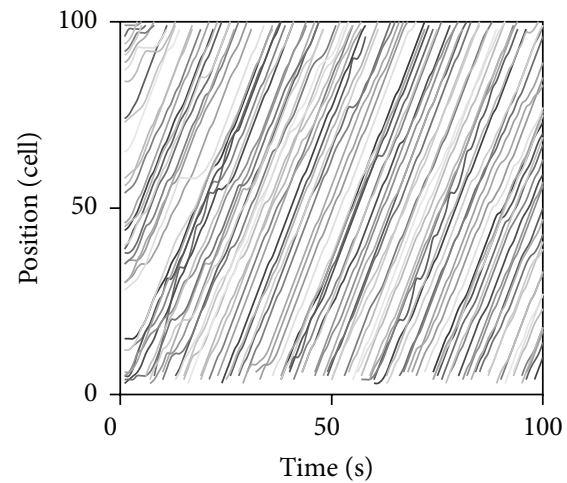

(a1) $R=20 \%, k=50 \mathrm{bic} / \mathrm{km} /$ lane

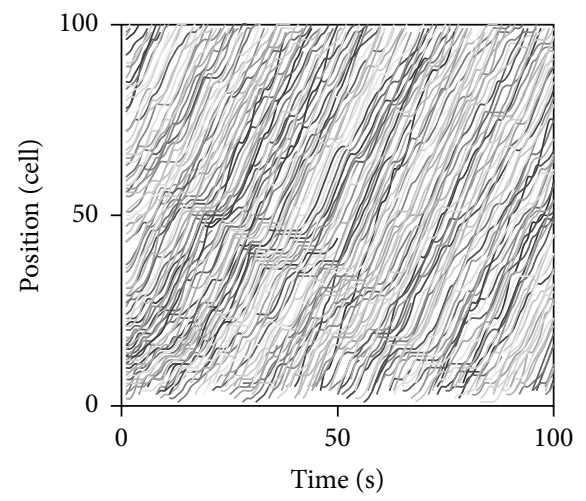

(a2) $R=20 \%, k=150 \mathrm{bic} / \mathrm{km} /$ lane

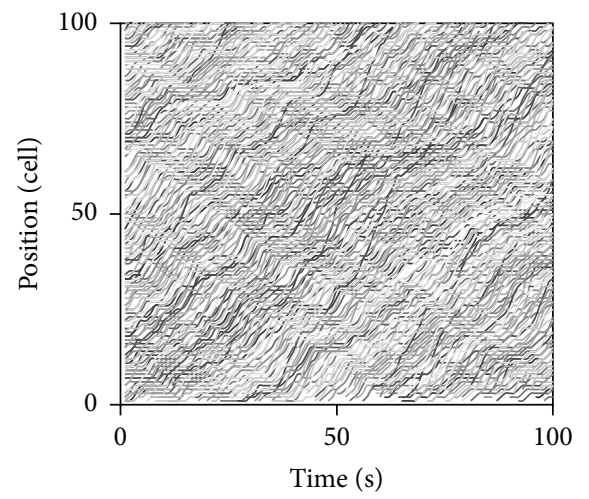

(a3) $R=20 \%, k=250 \mathrm{bic} / \mathrm{km} / \mathrm{lane}$

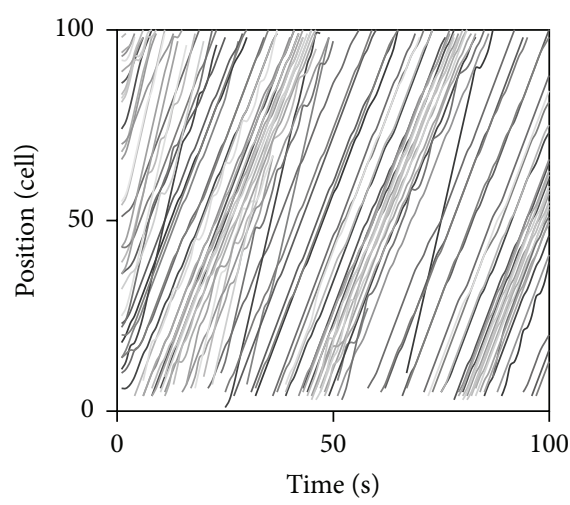

(b1) $R=50 \%, k=50 \mathrm{bic} / \mathrm{km} / \mathrm{lane}$

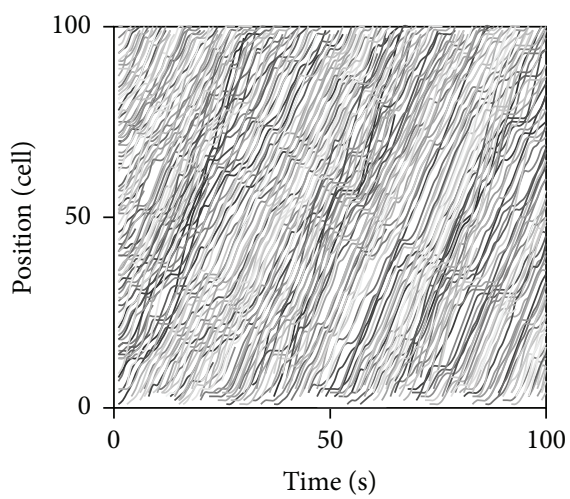

(b2) $R=50 \%, k=150 \mathrm{bic} / \mathrm{km} / \mathrm{lane}$

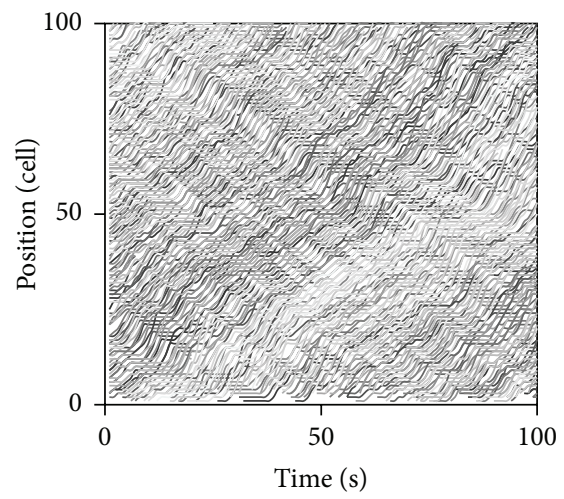

(b3) $R=50 \%, k=250 \mathrm{bic} / \mathrm{km} / \mathrm{lane}$

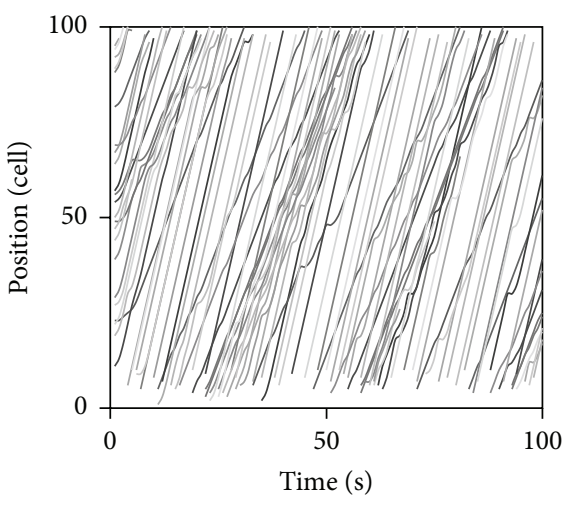

(c1) $R=80 \%, k=50 \mathrm{bic} / \mathrm{km} / \mathrm{lane}$

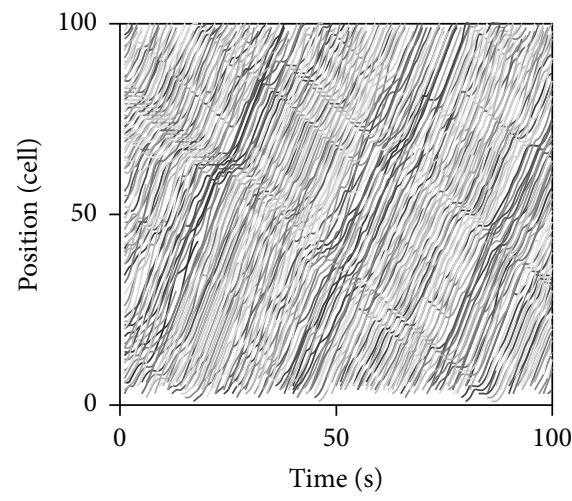

(c2) $R=80 \%, k=150 \mathrm{bic} / \mathrm{km} / \mathrm{lane}$

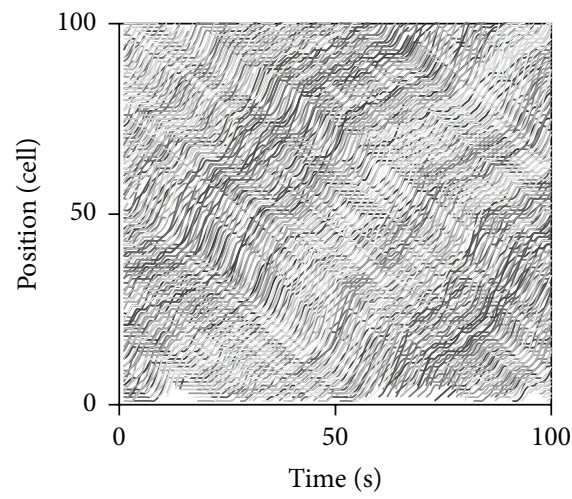

(c3) $R=80 \%, k=250 \mathrm{bic} / \mathrm{km} /$ lane

Figure 9: Traffic conditions with different proportions of e-bicycle.

be used to evaluate the traffic conditions on bicycle paths when traffic demands become larger in the future, to identify the congested bicycle paths to implement countermeasures. Second, our model can be used to analyze the bicycle traffic flow features with different proportions of electric bicycles, to support the decision for supporting or banning electric bicycles. Third, our model can be used to predict the number of passing events for the evaluation of level of service of bicycle traffic. Last but not least, our model can be used to analyze the change of bicycle traffic flow on bicycle paths with different travel lanes, to provide useful information for lane management on bicycle paths.
This study also has some limitations. In our study the congested traffic flow was not observed during field data collision so that the traffic flow features in congestion were not validated with filed data. Future study should collect bicycle traffic data with larger flow rates. Besides, this study only investigated traffic data on 3-lane bicycle paths. More data could be collected on more bicycle paths within more cities or countries to validate the simulation results of our model. Effects of personal characteristics to bicycle traffic flow features could be explored with considering the difference of maximum speeds of c-bicycles. Furthermore, some assumptions in the CA model could be relaxed to obtain more 


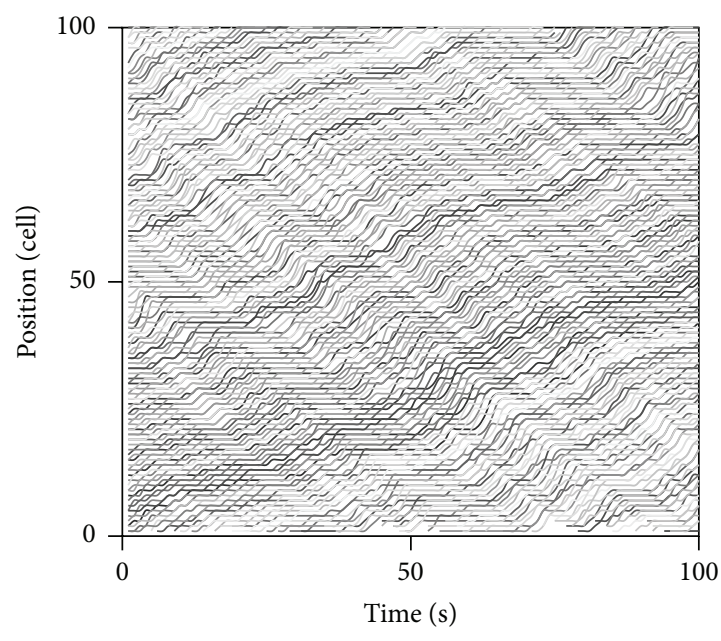

(a) Lane $=2, Q=4000 \mathrm{bic} / \mathrm{h}$

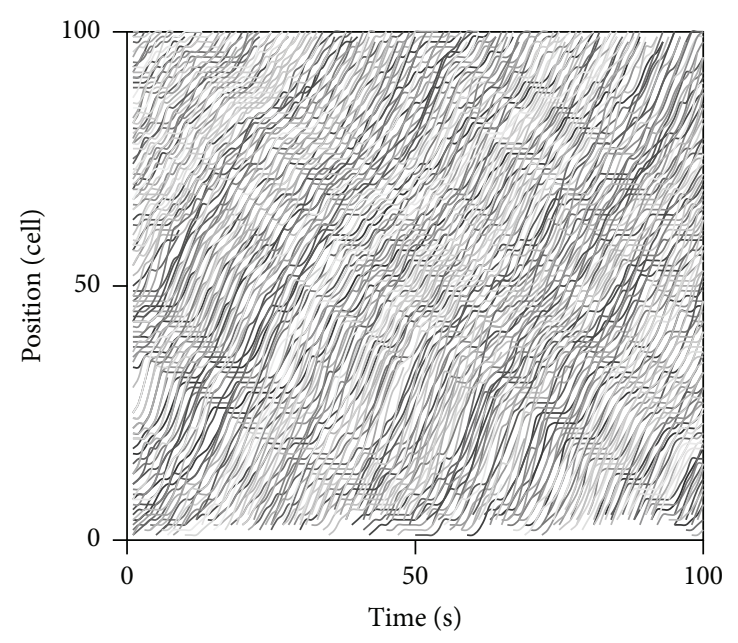

(b) Lane $=3, Q=4000 \mathrm{bic} / \mathrm{h}$

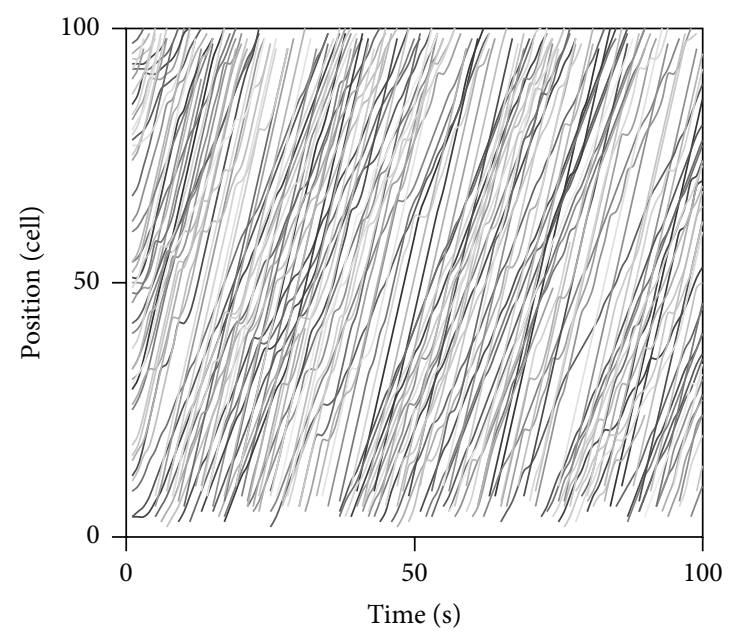

(c) Lane $=4, Q=4000 \mathrm{bic} / \mathrm{h}$

FIgURE 10: Traffic conditions on different travel lanes.

accurate simulation performances. The authors recommend that future research could focus on those issues.

\section{Conflict of Interests}

The authors declare that there is no conflict of interests regarding the publication of this paper.

\section{Acknowledgments}

This research is supported by the National Science Foundation of China (NSFC) (no. 51108342) and the National Natural Science Foundation of China (no. 51208253). The authors would like to thank the graduate students from School of Transportation Engineering, Tongji University, for their assistance in field data collection.

\section{References}

[1] Travel in London Report 5, Transport for London, 2012.

[2] City of New York, A Greener, Greater New York, City of New York, 2009.

[3] D. Taylor and W. Davis, "Review of basic research in bicycle traffic science, traffic operations, and facility design," Transportation Research Record, vol. 1674, pp. 102-115, 1999.

[4] R. Peng, Bicycle traffic flow theory [Ph.D. thesis], Transportation Engineering, Tongji Univeristy, Shanghai, China, 1993.

[5] C. Liang, Study on characteristics and application of bicycle traffic flow [Ph.D. thesis], Transportation Information Engineering and Control, Jilin University, Jilin, China, 2007.

[6] X. Chen, B. Lin, and H. Han, "Characteristics of mixed nonmotorized traffic flow: a comparative analysis with motorized and pedestrian traffic flow," in Proceedings of the 92nd TRB 
Annual Meeting Compendium of Papers, CD-ROM, Transportation Research Board of the National Academies, Washington, DC, USA, 2013.

[7] X. Chen, K. An, and L. Li, "Study on the influencing factors of bike lane capacity," in Proceedings of the TRB 93rd Annual Meeting Compendium of Papers, CD-ROM, Transportation Research Board of the National Academies, Washington, DC, USA, January 2014.

[8] X. Chen, H. Han, and B. Lin, "Developing bicycle equivalents for mopeds in Shanghai, China," Transportation Research Record, vol. 2317, pp. 60-67, 2012.

[9] S. Lin, M. He, Y. Tan, and M. He, "Comparison study on operating speeds of electric bicycles and bicycles experience from field investigation in Kunming, China," Transportation Research Record, vol. 2048, pp. 52-59, 2008.

[10] R. E. Miller and M. R. Ramey, Width Requirements for Bikeways: A Level of Service Approach, Department of Civil and Environmental Engineering, University of California, Davis, Calif, USA, 1975.

[11] W. S. Homburger, Capacity of Bus Routes, and of Pedestrian and Bicycle Facilities, Institute of Transportation Studies, University of California, Berkeley, Calif, USA, 1976.

[12] J. E. Hummer and N. M. Rouphail, Evaluation of Safety, Design, and Operation of Shared-Use Paths, FHWA-HRT-05-137, FHWA, U.S. Department of Transportation, 2006.

[13] "Highway capacity manual 2010," TRB Special Report 616, Transportation Research Board, National Research Council, Washington, DC, USA, 2010.

[14] Z. Li, W. Wang, P. Liu, J. Bigham, and D. R. Ragland, "Modeling bicycle passing maneuvers on multilane separated bicycle paths," Journal of Transportation Engineering, vol. 139, no. 1, pp. 57-64, 2013.

[15] X. Chen, B. Lin, X. Fang, and Y. Gao, "Occurrence and impact of passing maneuvers in non-motorized traffic mixed of bicycles and mopeds," in Proceedings of the TRB 93rd Annual Meeting Compendium of Papers, CD-ROM, Transportation Research Board of the National Academies, Washington, DC, USA, January 2014.

[16] D. Lin, X. Chen, B. Lin, and L. Li, "Phenomena and characteristics of moped-passing-bicycle on shared lanes," in Proceedings of the TRB 93rd Annual Meeting Compendium of Papers, Transportation Research Board of the National Academies, Washington, DC, USA, 2014.

[17] G. L. Khan and W. Raksuntorn, "Characteristics of passing and meeting maneuvers on exclusive bicycle paths," Transportation Research Record: Journal of the Transportation Research Board, vol. 1776, pp. 220-228, 2001.

[18] G. Gould and A. Karner, "Modeling bicycle facility operation: a cellular automaton approach," Transportation Research Record, vol. 2140, pp. 157-164, 2009.

[19] D. Zhao, W. C. Wang, C. Li, Z. Li, P. Fu, and X. Hu, "Modeling of passing events in mixed bicycle traffic with cellular automata," Transportation Research Record: Journal of the Transportation Research Board, vol. 2387, pp. 26-34, 2013.

[20] X.-G. Li, Z.-Y. Gao, B. Jia, and X.-M. Zhao, "Modeling the interaction between motorized vehicle and bicycle by using cellular automata model," International Journal of Modern Physics C, vol. 20, no. 2, pp. 209-222, 2009.

[21] X.-M. Zhao, B. Jia, Z.-Y. Gao, and R. Jiang, “Traffic interactions between motorized vehicles and nonmotorized vehicles near a bus stop," Journal of Transportation Engineering, vol. 135, no. 11, pp. 894-906, 2009.
[22] H. Han, Studies about characteristics of the mixed nonmotorized traffic flow and level of service of nonmotorized lane [Ph.D. thesis], Transportation Engineering, Tongji Univeristy, 2013.

[23] Code for Transport Planning on Urban Road, Ministry of Construction of the People's Republic of China, 1995.

[24] American Association of State Highway and Transportation Officials, Guide for the Planning, Design, and Operation of Bicycle Facilities, 2010.

[25] K. Nagel and M. Schreckenberg, "A cellular automaton model for freeway traffic," Journal De Physique I, vol. 2, no. 12, pp. 22212229, 1992.

[26] B. Jia, Z. Gao, K. Li, and X. Li, Models and Simulations of Traffic System Based on the Theory of Cellular Automaton, Science Press, Beijing, China, 2007.

[27] B. Jia, R. Jiang, Q.-S. Wu, and M.-B. Hu, "Honk effect in the two-lane cellular automaton model for traffic flow," Physica A: Statistical Mechanics and Its Applications, vol. 348, pp. 544-552, 2005.

[28] A. K. Daoudia and N. Moussa, "Numerical simulations of a three-lane traffic model using cellular automata," Chinese Journal of Physics, vol. 41, no. 6, pp. 671-682, 2003.

[29] M. M. Pedersen and P. T. Ruhoff, "Entry ramps in the NagelSchreckenberg model," Physical Review E, vol. 65, no. 2, Article ID 056705, 9 pages, 2002.

[30] Y. Hollander and R. H. Liu, "The principles of calibrating traffic microsimulation models," Transportation, vol. 35, no. 3, pp. 347362, 2008.

[31] T. Ma and B. Abdulhai, "Genetic algorithm-based optimization approach and generic tool for calibrating traffic microscopic simulation parameters," Transportation Research Record, vol. 1800, pp. 6-15, 2002.

[32] M. K. Rickert, K. Nagel, M. Schreckenberg, and A. Latour, "Two lane traffic simulations using cellular automata," Physica A: Statistical Mechanics and Its Applications, vol. 231, no. 4, pp. 534-550, 1996. 


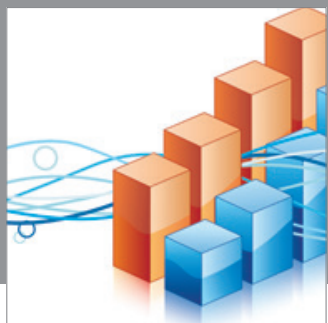

Advances in

Operations Research

mansans

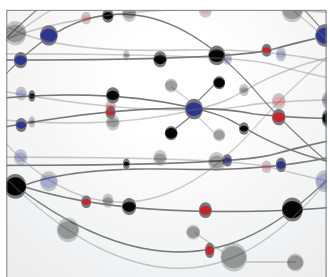

The Scientific World Journal
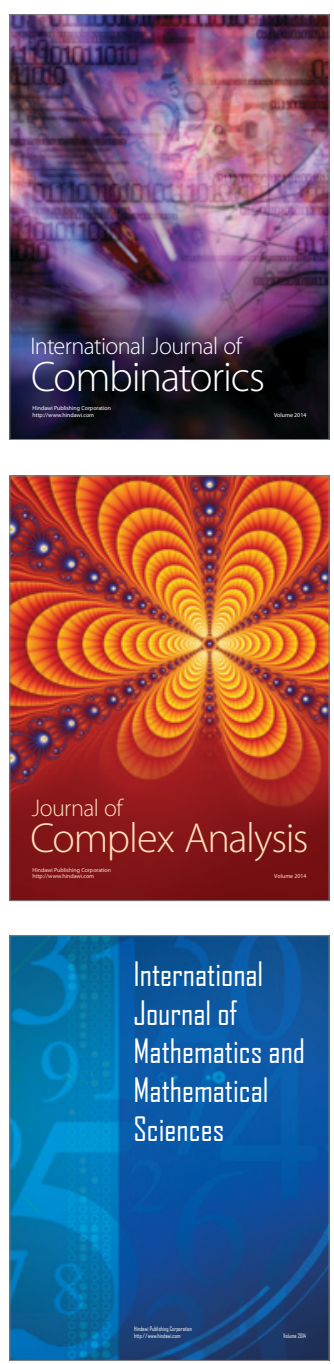
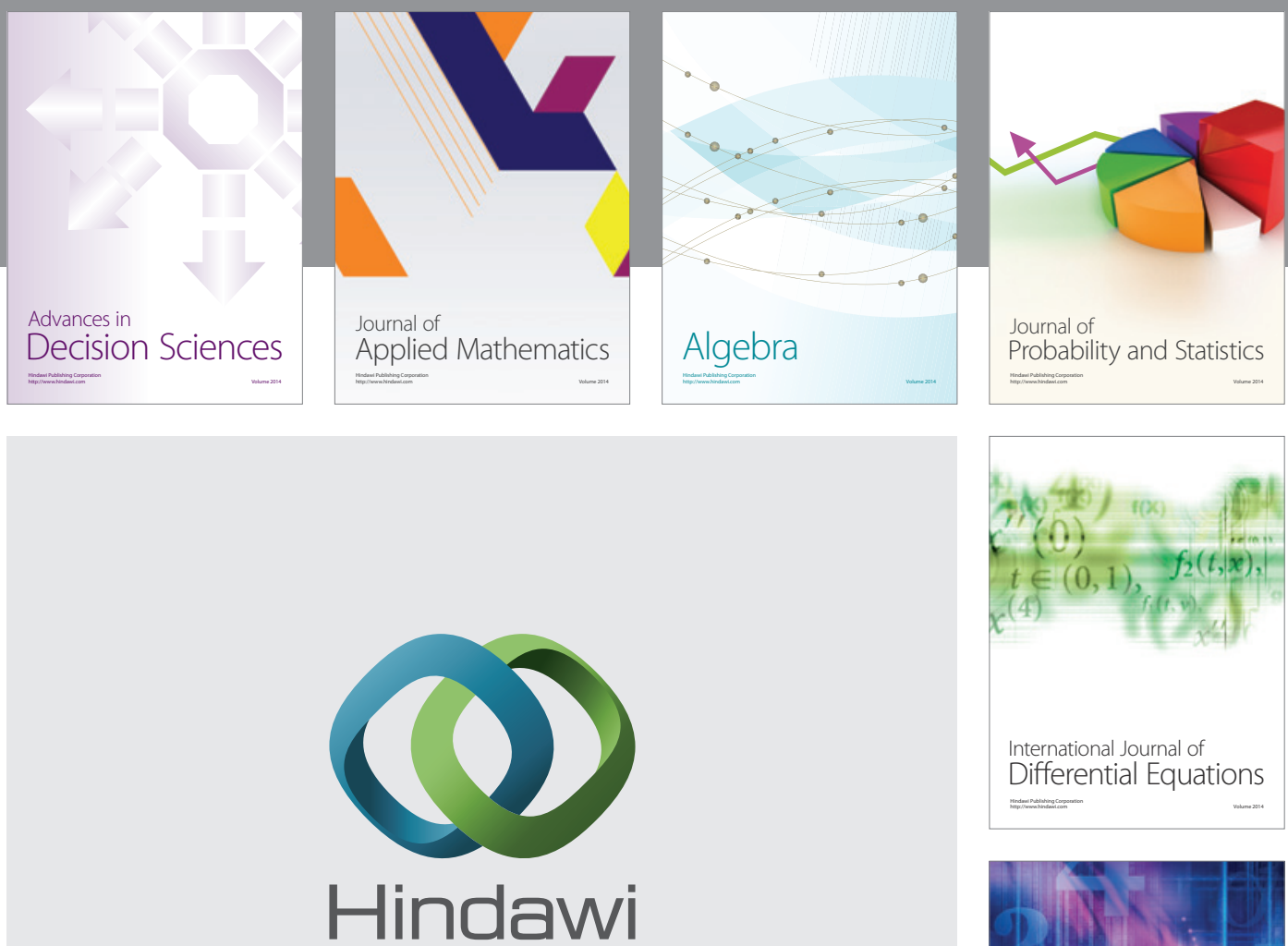

Submit your manuscripts at http://www.hindawi.com
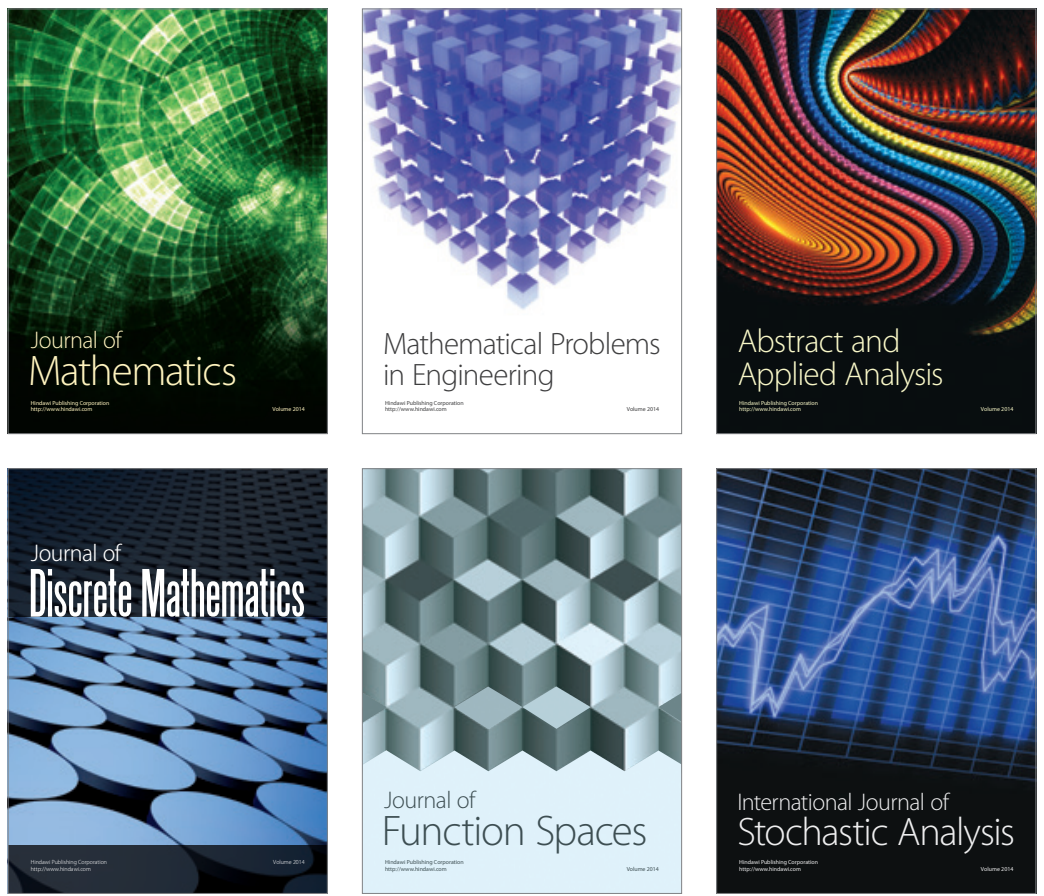

Journal of

Function Spaces

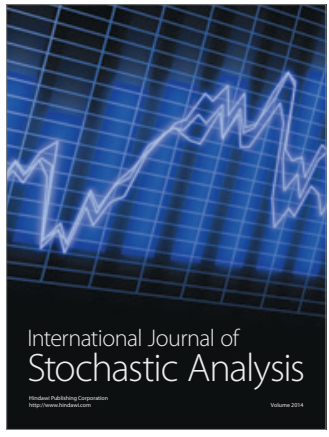

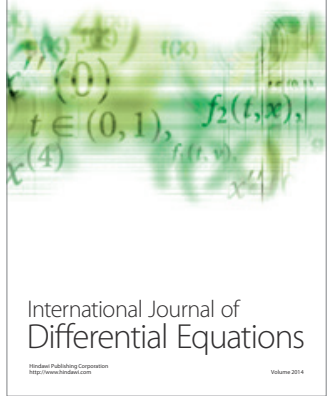
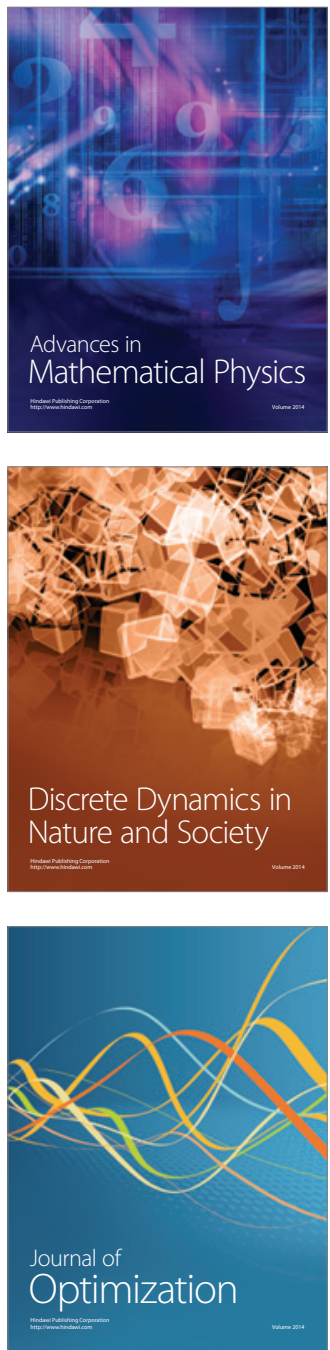